\title{
Case Report: Acute hemorrhagic edema of infancy
}

\section{(Seidlmayer purpura) - a dramatic presentation for a benign}

\section{disease [version 1; peer review: 2 approved]}

\author{
Elena Carboni ${ }^{1}$, Maria Scavone1, Ettore Stefanelli ${ }^{1}$, Valentina Talarico (i)2, \\ Stefania Zampogna², Maria Concetta Galati ${ }^{3}$, Giuseppe Raiola ${ }^{2}$ \\ ${ }^{1}$ Department of Pediatrics, Magna Graecia University of Catanzaro, Catanzaro, Italy \\ 2Department of Pediatrics, Pugliese Ciaccio Hospital, Catanzaro, Italy \\ ${ }^{3}$ Department of Pediatric Oncology and Hematology, Pugliese Ciaccio Hospital, Catanzaro, Italy
}

V1 First published: 17 Oct 2019, 8:1771

https://doi.org/10.12688/f1000research.20645.1

Latest published: 17 Oct 2019, 8:1771

https://doi.org/10.12688/f1000research.20645.1

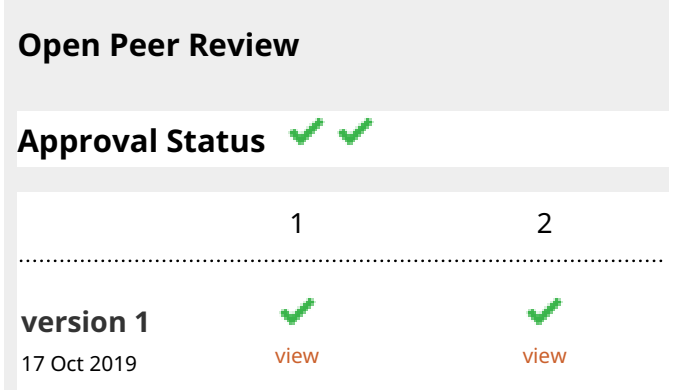

1. Mario Bianchetti, Università della Svizzera italiana, Lugano, Switzerland

2. Antonio Francesco Urbino, Regina Margherita Children's Hospital, A.O.U. Città della Salute e della Scienza di Torino, Turin, Italy

Any reports and responses or comments on the article can be found at the end of the article. 
Corresponding author: Valentina Talarico (talaricovalentina@gmail.com)

Author roles: Carboni E: Conceptualization, Supervision, Validation, Visualization, Writing - Original Draft Preparation, Writing - Review \& Editing; Scavone M: Conceptualization, Data Curation, Validation, Visualization, Writing - Original Draft Preparation, Writing - Review \& Editing; Stefanelli E: Conceptualization, Data Curation, Visualization, Writing - Original Draft Preparation, Writing - Review \& Editing; Talarico V: Conceptualization, Data Curation, Supervision, Validation, Visualization, Writing - Original Draft Preparation, Writing - Review \& Editing; Zampogna S: Conceptualization, Validation, Writing - Review \& Editing; Galati MC: Conceptualization, Validation, Visualization, Writing - Review \& Editing; Raiola G: Conceptualization, Validation, Visualization, Writing - Original Draft Preparation, Writing - Review \& Editing

Competing interests: No competing interests were disclosed.

Grant information: The author(s) declared that no grants were involved in supporting this work.

Copyright: ( 2019 Carboni E et al. This is an open access article distributed under the terms of the Creative Commons Attribution License, which permits unrestricted use, distribution, and reproduction in any medium, provided the original work is properly cited.

How to cite this article: Carboni E, Scavone M, Stefanelli E et al. Case Report: Acute hemorrhagic edema of infancy (Seidlmayer purpura) - a dramatic presentation for a benign disease [version 1; peer review: 2 approved] F1000Research 2019, 8:1771 https://doi.org/10.12688/f1000research.20645.1

First published: 17 Oct 2019, 8:1771 https://doi.org/10.12688/f1000research.20645.1 


\section{Introduction}

Acute hemorrhagic edema of infancy (AHEI), also known as Seidlmayer purpura, is a rare cutaneous leukocytoclastic vasculitis. It was described for the first time in 1913 and currently there are more than 300 cases in the literature ${ }^{1}$. Initially it has been interpreted as a Henoch-Schönlein purpura variant, but now it is considered a distinct disease. Although it has a dramatic clinical presentation, it is a benign and selflimited disease ${ }^{2}$. We report the case of an 11-month-old girl who was referred to our unit for an erythematous rash appeared on the face and extremities, which was indicative of a rare but non negligible diagnosis.

\section{Case presentation}

An 11-month-old girl from France presented with fever and oval purpuric lesions on the face and extremities, which had appeared one hour before. In the previous week, she had bilateral conjunctivitis and gastroenteritis, treated with oral rehydration. At admission she was in good clinical condition and her vital signs were normal. Physical examination showed purpuric confluent elements with a cockade pattern on cheeks, left auricle, upper and lower limbs, particularly on distal ends, sparing trunk and back (Figure 1). Hands appeared edematous without joint swelling or tenderness. Bilateral conjunctivitis was still present. No other physical abnormalities were observed. Complete blood count, extended biochemistry, coagulation tests (prothrombin time, partial thromboplastin time, fibrinogen and D-dimer) and urinalysis were normal with C-reactive protein of $18.9 \mathrm{mg} / \mathrm{l}$ (normal value $<5 \mathrm{mg} / \mathrm{l}$ ) and procalcitonin of $0.88 \mathrm{ng} / \mathrm{ml}$ (normal value $<0.05 \mathrm{ng} / \mathrm{ml}$ ). During the hospitalization the child maintained good clinical condition, with stable vital parameters. Dermatological lesions showed a worsening clinical outcome, with increased diameter and colour intensity during the following three days from admission. Based on clinical and laboratory findings, a diagnosis of AHEI was made. We decided to not perform any therapy and after about two weeks lesions had a self-limited resolution. The child was monitored

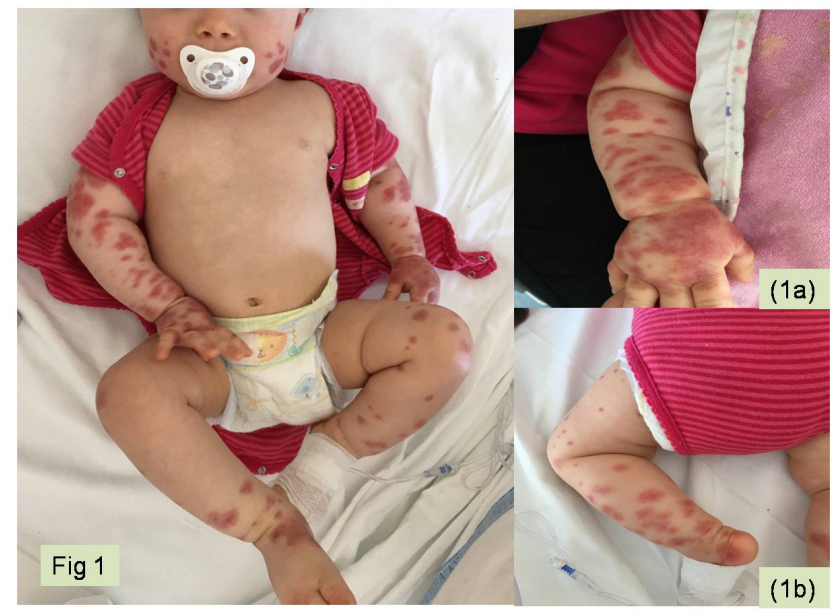

Figure 1. Cutaneous presentation of acute hemorrhagic edema of infancy in our case. (a) Ecchymotic target-like skin lesions with edema of the hand. (b) Purpuric confluent elements with a cockade pattern on the lower limbs. clinically for about six months and she did not present any relapse of the disease during the follow-up period.

\section{Discussion}

The first description of AHEI was made by Snow in $1913^{1}$. There have been approximately 300 cases reported in the literature ${ }^{2}$ under a variety of denominations: Seidlmayer purpura, Finkelstein disease, rosette form purpura, medallion-like purpura, infantile post-infectious iris-like purpura and edema ${ }^{3}$. AHEI is a rare cutaneous leukocytoclastic vasculitis that usually affects children aged between 4 and 24 months and it is more common in males ${ }^{2,4}$. Most cases of AHEI occur during winter, and almost of $75 \%$ of cases are preceded by infectious episodes, such as viral and bacterial infections of the upper respiratory tract, otitis media, conjunctivitis, bronchopneumonia, urinary tract infections and enteritis. Many organisms including adenovirus, varicella zoster virus, cytomegalovirus, rotavirus, herpes simplex virus, tuberculosis, streptococci, and staphylococci are associated with AHEI. Vaccinations or medications could also trigger $\mathrm{AHEI}^{5}$. In this case, the patient had a weeklong history of bilateral conjunctivitis and gastroenteritis, compatible with a recent viral infection. A peculiar feature of AHEI is the unusual dramatic cutaneous eruption that contrasts with good general clinical condition (normal vital parameters with normal blood tests) that allowed to exclude more serious diseases. Diagnosis is clinical and it is classically detectable by observance of the clinical triad of symptoms: fever, edema and purpura $^{6}$. Skin lesions are erythematous, annular, medallionlike, rosette-shaped purpuric plaques that cluster and often coalesce $^{3}$. These lesions have a rapid onset and appear on face and extremities, sparing trunk and mucosal membranes ${ }^{3,4}$. The edema typically occurs on feet, hands, face and auricles, and can involve the scrotum in males ${ }^{2,7}$. In the majority of cases there is no visceral involvement and the disease is benign and self-limited. However, in the literature there are descriptions of cases of renal involvement, arthralgias and two cases of intestinal involvement followed by intussusception ${ }^{2}$.

Krause et al. suggested the following criteria for diagnosing AHEI $^{8}$ :

- Age <2 years;

- Purpuric or ecchymotic target-like skin lesions with edema on the head and face, with or without mucosal involvement;

- Lack of systemic disease or visceral involvement;

- Spontaneous recovery within few days or weeks.

Our patient presented all of the above conditions. Laboratory data are usually normal, but leukocytosis, thrombocytosis, eosinophilia and high levels of C-reactive protein and erythrocyte sedimentation rate can be observed ${ }^{7}$. Skin biopsy shows a leukocytoclastic vasculitis of the small dermal vessels characterized by infiltration of perivascular neutrophils, showing fragmentation of nuclei, resulting in fibrinoid necrosis9. Differential diagnoses include urticaria, erythema multiforme, idiopathic thrombocytopenia, meningococcemia, Kawasaki 
disease, Sweet syndrome, Gianotti-Crosti disease, drug-induced vasculitis, child abuse and trauma-induced purpura, but HenochSchönlein purpura is probably the most important ${ }^{9,10}$. Initially interpreted as a variant of Henoch-Schnölein purpura, now it is considered a distinct disease with different epidemiological, clinical and pathological features ${ }^{4}$.

Treatment of AHEI remains controversial; conservative management is the most frequently approach, because this disease is a self-limited condition ${ }^{4,7,9}$. AHEI certainly represents a challenge for the pediatrician at the emergency department and it requires, at least initially, a high level of suspicion for potentially serious pathologies that need adequate, urgent treatment such as for infectious (meningococcemia) or hematological diseases (autoimmune thrombocytopenia, coagulopathies). In fact, in our case some easily laboratory tests, such as complete blood count, prothrombin time, partial thromboplastin time, fibrinogen, D-dimer, C-reactive protein and procalcitonin tests were supportive in the rapid exclusion of these conditions. This approach, together with the typical benign course of the AHEI, quickly guaranteed the exclusion of these conditions, avoiding the execution of unnecessary and/or invasive diagnostic procedures and unrequired therapies.
We reported this case because it is expression of a rare and often under-recognized disease by pediatricians. A typical feature of AHEI is the discrepancy between dramatic cutaneous involvement and good clinical conditions of the affected children. This characteristic can reassure clinicians about the absence of a serious medical condition, but it is possible only through the knowledge of the disease.

\section{Conclusion}

We describe a case of AHEI with striking cutaneous involvement that resolved spontaneously. AHEI is an uncommon disease, often under-recognized. For this reason, it is crucial that physicians have the skill to recognize this self-limited disease to avoid parental anxiety and inappropriate procedures or therapies.

\section{Data availability}

All data underlying the results are available as part of the article and no additional source data are required.

\section{Consent}

We received written informed consent from the patient's family for the publication of this manuscript.
1. Snow IM: Purpura, urticaria and angioneurotic edema of the hands and feet in a nursing baby. JAMA. 1913; 61(1): 18-9. Publisher Full Text

2. Fiore $\mathrm{E}$, Rizzi M, Ragazzi M, et al:: Acute hemorrhagic edema of young children (cockade purpura and edema): a case series and systematic review. J Am Acad Dermatol. 2008; 59(4): 684-695. PubMed Abstract | Publisher Full Text

3. Homme JL, Block JM: Acute hemorrhagic edema of infancy and common mimics. Am J Emerg Med. 2016; 34(5): 936.e3-6. PubMed Abstract | Publisher Full Text

4. Cunha DF, Darcie AL, Benevides GN, et al:: Acute Hemorrhagic Edema of Infancy: an unusual diagnosis for the general pediatrician. Autopsy Case Rep. 2015; 5(3): 37-41.

PubMed Abstract | Publisher Full Text | Free Full Text

5. Fotis L, Nikorelou S, Lariou MS, et al: Acute hemorrhagic edema of infancy: a frightening but benign disease. Clin Pediatr (Phila). 2012; 51(4): 391-3. PubMed Abstract | Publisher Full Text
6. Miorin E, Meneghini A, Don B, et al.: Edema emorragico acuto del lattante, descrizione di un caso clinico e revisione della letteratura. Medico e Bambino pagine elettroniche. 2002; 5 (3). Reference Source

7. Alhammadi AH, Adel A, Hendaus MA: Acute hemorrhagic edema of infancy: a worrisome presentation, but benign course. Clin Cosmet Investig Dermatol. 2013; 6: 197-9.

PubMed Abstract | Publisher Full Text | Free Full Text

8. Krause I, Lazarov A, Rachmel A, et al:: Acute haemorrhagic oedema of infancy, a benign variant of leucocytoclastic vasculitis. Acta Paediatr. 1996; 85(1): 114-7. PubMed Abstract | Publisher Full Text

9. Savino F, Lupica MM, Tarasco V, et al.: Acute hemorrhagic edema of infancy: a troubling cutaneous presentation with a self-limiting course. Pediatr Dermatol. 2013; 30(6): e149-52. PubMed Abstract | Publisher Full Text

10. Tagliabue A, Bettinelli A, Cogliati F: Edema acuto emorragico della prima infanzia (porpora di seidlmayer). Medico e Bambino pagine elettroniche. 2009; 12(6). Reference Source 


\section{Open Peer Review}

\section{Current Peer Review Status:}

\section{Version 1}

Reviewer Report 27 December 2019

https://doi.org/10.5256/f1000research.22706.r57605

(C) 2019 Urbino A. This is an open access peer review report distributed under the terms of the Creative Commons Attribution License, which permits unrestricted use, distribution, and reproduction in any medium, provided the original work is properly cited.

\section{Antonio Francesco Urbino}

Department of Pediatric Emergency, Regina Margherita Children's Hospital, A.O.U. Città della Salute e della Scienza di Torino, Turin, Italy

The case report is interesting, well written and provides complete information for paediatricians who have never met the acute hemorrhagic edema of infancy in their practice.

Just a few minor observations:

1. The acute hemorrhagic edema of infancy is more known as Finkelstein disease than as Seidlmayer purpura: I suggest to change the eponym both in the introduction and in the keywords.

2. The French origin of the girl does not influence the diagnosis and is redundant: please remove it.

3. In the discussion section, Finkelstein disease is said to be distinguished from Gianotti-Crosti disease, whose papular and not usually purpuric presentation is quite different: I suggest to remove it.

4. Authors state the the Finkelstein disease is more frequent in winter time: when did the girl arrived in the Emergency Department?

Is the background of the case's history and progression described in sufficient detail? Yes

Are enough details provided of any physical examination and diagnostic tests, treatment given and outcomes?

Yes

Is sufficient discussion included of the importance of the findings and their relevance to future understanding of disease processes, diagnosis or treatment? 
Yes

Is the case presented with sufficient detail to be useful for other practitioners?

Yes

Competing Interests: No competing interests were disclosed.

Reviewer Expertise: Pediatric Emergency specialist

I confirm that I have read this submission and believe that I have an appropriate level of expertise to confirm that it is of an acceptable scientific standard.

Reviewer Report 09 December 2019

https://doi.org/10.5256/f1000research.22706.r57576

(C) 2019 Bianchetti M. This is an open access peer review report distributed under the terms of the Creative Commons Attribution License, which permits unrestricted use, distribution, and reproduction in any medium, provided the original work is properly cited.

\section{Mario Bianchetti}

Università della Svizzera italiana, Lugano, Switzerland

The case report entitled "Acute hemorrhagic edema of infancy (Seidlmayer purpura) - a dramatic presentation for a benign disease" is interesting and rather well-presented. The following 12 changes might ameliorate the attractiveness of the report:

1. The term "Seidlmayer purpura" is popular in Germany (and perhaps in Italy). Most authors use the term "Finkelstein-Seidlmayer purpura" (Finkelstein reported his case in 1929, Seidlmayer in 1939). Please modify the manuscript accordingly.

2. Present manuscript: "...is a rare cutaneous leukocytoclastic vasculitis."

My suggestion: “...is a rare small vessel cutaneous leukocytoclastic vasculitis affecting infants 4 weeks to 24 months of age."

3. Statement: "Initially it has been interpreted as a Henoch-Schönlein purpura variant, but now it is considered a distinct disease." Remove this statement from the Introduction section (this issue is addressed in the Discussion section).

4. Statement: "An 11-month-old girl from France presented with fever and oval purpuric lesions on the face and extremities, which had appeared one hour before." Please provide temperature value or at least "moderate" respectively "high" fever (furthermore: state either "axillary" or "rectal"). 
5. Skin lesions are sometimes painful in Finkelstein-Seidlmayer disease. I wonder if lesions were painful in this case (important information).

6. Was pruritus present (it is usually absent in this vasculitis)?

7. Statement: "Many organisms including adenovirus, varicella zoster virus, cytomegalovirus, rotavirus, herpes simplex virus, tuberculosis, streptococci, and staphylococci are associated with AHEI."

My suggestion: remove "tuberculosis" (because tuberculosis has never been associated with this vasculitis after 1969).

8. Statement: "Vaccinations or medications could also trigger AHEI". However, no cases of AHEI have been causally associated, to the best of my knowledge, with the medications.

My suggestion: modify the statement accordingly.

9. Statement: "In the majority of cases there is no visceral involvement and the disease is benign and self-limited."

My suggestion: "In the vast majority of cases there is no visceral involvement and the disease is benign and self-limited.

10. The statement "Treatment of AHEI remains controversial; conservative management is the most frequently approach, because this disease is a self-limited condition" is poorly presented.

My suggestion: AHEI is a self-limited condition. The lesions disappear within 3 weeks in $\geq 80 \%$ of the cases. Systemic steroids, non-steroidal anti-inflammatory drugs or antihistamines are prescribed in many cases. It is currently assumed, however, that these drugs do not alter the disease course. Once the diagnosis is established, supportive care and reassurance are advised.

11. The total length of the current report is excessive (please reduce the total length by $\geq 10 \%$ ).

12. References:

- Please remove references number 6 (Miorin) and number 10 (Tagliabue) because they were not published in English language (local journals).

- Please add the following new reference: Lava et al. (2017¹) (recent review, more up-to-date than current reference number 2.) 


\section{References}

1. Lava S, Milani G, Fossali E, Simonetti G, et al.: Cutaneous Manifestations of Small-Vessel Leukocytoclastic Vasculitides in Childhood. Clinical Reviews in Allergy \& Immunology. 2017; 53 (3): 439-451 Publisher Full Text

Is the background of the case's history and progression described in sufficient detail? Yes

Are enough details provided of any physical examination and diagnostic tests, treatment given and outcomes?

Yes

Is sufficient discussion included of the importance of the findings and their relevance to future understanding of disease processes, diagnosis or treatment?

Yes

Is the case presented with sufficient detail to be useful for other practitioners?

Yes

Competing Interests: No competing interests were disclosed.

Reviewer Expertise: Pediatric kidney disease specialist with broad expertise with "childhood vasculitis"

I confirm that I have read this submission and believe that I have an appropriate level of expertise to confirm that it is of an acceptable scientific standard.

The benefits of publishing with F1000Research:

- Your article is published within days, with no editorial bias

- You can publish traditional articles, null/negative results, case reports, data notes and more

- The peer review process is transparent and collaborative

- Your article is indexed in PubMed after passing peer review

- Dedicated customer support at every stage

For pre-submission enquiries, contact research@f1000.com 